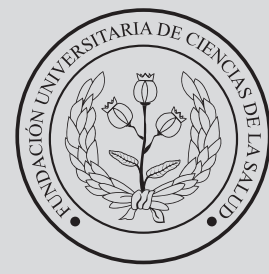

FUCS

\section{Re}

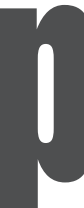

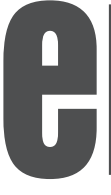

\section{de}

1c to

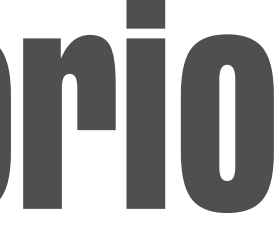

28

Artículo de investigación

\title{
Células del cuello uterino con atipias que no descartan una lesión de alto grado (ASC-H) con premalignidad
}

Margelys Peña ${ }^{a}$ Génesis Moreno ${ }^{\mathrm{a}}$ Morelva Toro de Méndez MD ${ }^{\mathrm{b}}$ Juan Márquez ${ }^{\mathrm{C}}$

\section{Cervical atypical cells-cannot exclude a premalignant high-grade lesion (ASC-H)}

${ }^{a}$ Facultad de Farmacia y Bioanálisis, Universidad de Los Andes, Mérida-Venezuela.

${ }^{b}$ Bioanalista-Citóloga. Doctora en Patología de los Tumores Humanos. "Grupo de Investigaciones Citológicas". Cátedra de Citología. Facultad de Farmacia y Bioanálisis, Universidad de Los Andes. Mérida-Venezuela.

${ }^{c}$ Magister Scientiae en Estadística Aplicada, Unidad de Bioestadística de la Escuela de Nutrición y Dietética. Facultad de Medicina.

Universidad de Los Andes. Mérida-Venezuela

\section{R ES U M E N}

Introducción: la presencia de células escamosas con atipias que no descartan una lesión intraepitelial escamosa de alto grado (ASC-H) es significativa, pues cerca de $50 \%$ podrían corresponder a una lesión premaligna del cérvix uterino. Objetivo: describir las alteraciones citomorfológicas más frecuentes en los extendidos citológicos categorizados como células escamosas con atipias que no descartan una lesión intraepitelial escamosa de alto grado (ASC-H), con existencia de lesión clínicamente significativa en el resultado histopatológico. Metodología: estudio retrospectivo en el laboratorio de citología de la Facultad de Farmacia y Bioanálisis, Universidad de Los Andes y Clínica de Prevención del Cáncer de la Sociedad Anticancerosa, Mérida-Venezuela, de los casos analizados entre enero 2010 y diciembre 2016 con resultados citológicos cervicales ASC-H. Resultados: 35,8\% (19/53) de los casos presentaron un resultado histopatológico anormal: 22,6\% solo infección por HPV y 13,2\% una lesión premaligna (CIN) combinada con infección por HPV. El 73,7\% con CIN y/o HPV presentó células metaplásicas inmaduras atípicas con hipercromasia (78,6\%), anisocariosis $(100 \%)$, cromatina y membrana irregular $(92,9 \%)$, sobre fondo de frotis no inflamatorio. Conclusiones: las alteraciones citomorfológicas más frecuentes en los extendidos citológicos de cuello uterino categorizadas como ASC-H y significativamente

INFORMACIÓN DEL ARTÍCULO

Historia del artículo:

Fecha recibido: enero 11 de 2019 Fecha aceptado: mayo 17 de 2019

\footnotetext{
Autor para correspondencia. Margelys Peña marge17.mpa@gmail.com
}

DOI

10.31260/RepertMedCir.v28.n3.2019.957 
asociadas con lesión en el resultado histopatológico fueron: anisocariosis, hipercromasia, cromatina y membrana nuclear irregular, sobre un fondo de frotis limpio. Las mismas atipias fueron comunes en los grupos con CIN 1, 2 o 3 y/o HPV, con diferencias estadísticas significativas $(\mathrm{p}<0,05)$.

Palabras clave: ASC-H, citología de cuello uterino, criterios cito-morfológicos, lesiones premalignas

(C) 2019 Fundación Universitaria de Ciencias de la Salud - FUCS. Este es un artículo Open Access bajo la licencia CC BY-NC-ND (http://creativecommons.org/licenses/by-nc-nd/4.0/).

\section{A BS T R ACT}

Introduction: the presence of atypical squamous cells-cannot exclude a high-grade squamous intraepithelial lesion (ASC-H) is significant, for approximately 50\% could correspond to a cervix premalignant lesion. Objective: to describe the most frequent cytomorphological alterations on cervical cytology categorized as ASC-H, associated with a clinically significant histologically proven lesion. Methodology: this was a retrospective study performed at the cytology laboratory of the School of Pharmacy and Bioanalysis of Andes University and the Cancer Prevention Clinic of the Anti-Cancer Society in Merida-Venezuela, on cases with an ASC-H result on cervical cytology, analyzed between January 2010 and December 2016. Results: abnormal histopathological results were found in $35.8 \%$ (19/53) of cases: $22.6 \%$ had only an infection by HPV and $13.2 \%$ a premalignant lesion (CIN) combined with a HPV infection. 73.7\% with CIN and/or HPV presented atypical immature metaplastic cells with hyperchromasia (78\%), anisokaryosis $(100 \%)$, and irregular nuclear membrane chromatin $(92.9 \%)$, on a non-inflammatory background. Conclusions: the most frequent cytomorphological alterations on cervical cytology categorized as ASC-H associated with a significant histologically proven lesion were: anisokaryosis, hyperchromasia and irregular nuclear membrane chromatin, on a clean background. The same atypical cells were common in the CIN 1, 2 or 3 and/or HPV groups, showing statistical significant differences ( $<<0.05)$.

Key words: ASC-H, cervical cytology, cytomorphological criteria, premalignant lesions

(C) 2019 Fundación Universitaria de Ciencias de la Salud - FUCS. This is an open access article under the CC BY-NC-ND license (http://creativecommons.org/licenses/by-nc-nd/4.0/).

\section{INTRODUCCIÓN}

La citología vaginal se ha utilizado a nivel mundial para la pesquisa del cáncer de cuello uterino y de las alteraciones premalignas conocidas como lesión intraepitelial escamosa $(S I L)$ denominadas en histopatología neoplasia intraepitelial cervical $(C I N)$. La presencia de células escamosas con atipias que no descartan una lesión intraepitelial escamosa de alto grado $(A S C-H)$ es significativa, ya que cerca de $50 \%$ de las pacientes podrían presentar una lesión premaligna. ${ }^{1,2} \mathrm{El}$ sistema Bethesda establece con claridad los criterios citomorfológicos que definen y caracterizan a las categorizadas como ASC-H. Estos criterios se observan en células epiteliales inmaduras, escamosas y/o metaplásicas, de manera parcial y combinada, con alteraciones que cualitativa o cuantitativamente son insuficientes para un diagnóstico definitivo de lesión intraepitelial escamosa de alto grado (HSIL). Las células pueden disponerse en forma aislada o agrupadas, con pérdida de la polaridad y ligera superposición nuclear. El núcleo es 1,5 a 2 veces mayor que el de una célula metaplásica o profunda normal, con incremento de la relación núcleo/citoplasma, membrana nuclear y cromatina ligeramente irregulares o con hipercromasia nuclear de variable intensidad. El fondo del frotis por lo general es limpio, sin inflamación o pueden verse eritrocitos bien preservados.,
En general, la proporción de resultados citológicos interpretados como $A S C-H$ es baja, siendo su incidencia menor de $1 \%$ y su variabilidad en la literatura universal entre $0,11 \%$ y $0,39 \% .^{1,5-8}$ La subcategoría de anormalidades en células escamosas $A S C-H$ constituye un hallazgo citológico sugestivo o sospechoso de HSIL, más no un diagnóstico definitivo, aunque se ha demostrado que tiene un mayor valor predictivo positivo para detectar CIN 2 ó 3 oculta en el seguimiento clínico (más del 40\%), en comparación con aquellos casos interpretados como atipias inespecíficas o $A S C$ US. ${ }^{1,4,6,9,10}$ Así mismo, estudios realizados han demostrado que las interpretaciones citológicas tanto ASC-US, ASC-H y $A G C$ también podrían estar asociadas con la presencia de $H P V$ oncogénico. ${ }^{11,12}$ Por tanto, un hallazgo de células epiteliales atípicas y su evaluación oportuna podría contribuir en la prevención del cáncer invasor de cuello uterino. El objetivo de este estudio fue describir las alteraciones citomorfológicas más frecuentes en los extendidos citológicos de cuello uterino categorizados como células escamosas con atipias que no descartan una lesión intraepitelial escamosa de alto grado $(A S C-H)$, con existencia de lesión clínicamente significativa en el resultado histopatológico. 


\section{MATERIAL Y METODOLOGÍA}

En el laboratorio docente asistencial y de investigación de la cátedra de citología de la Facultad de Farmacia y Bioanálisis, Universidad de Los Andes, Mérida, se seleccionaron de manera retrospectiva los informes y extendidos citológicos de cuello uterino clasificados como ASC-H según los criterios citomorfológicos del sistema Bethesda $\mathrm{a}^{4}$, pertenecientes a las pacientes que acudieron a la consulta de la clínica de prevención del cáncer, de la Sociedad Anticancerosa, Capitulo Mérida-Venezuela, durante el periodo comprendido entre enero 2010 y diciembre 2016, cuyos datos clínicoepidemiológicos se encontraban completos y disponibles en sus respectivas historias clínicas. Los extendidos citológicos fueron reevaluadas por un citólogo con más de 20 años de experiencia; las láminas no fueron teñidas nuevamente, pues estaban montadas con laminillas y bien preservadas. Los datos obtenidos fueron incluidos en excel y analizados mediante estadística descriptiva usando el paquete estadístico SPSS, versión 20.0; Un valor $p<0,050$ fue considerado estadísticamente significativo. Para ver la significancia estadística, se utilizó estadística no paramétrica a través de una prueba binomial para una muestra. El consentimiento informado de las pacientes no fue necesario ya que no estuvieron involucradas directamente en este estudio.

\section{RES ULTADOS}

En el laboratorio docente, asistencial y de investigación de la cátedra de citología de la Facultad de Farmacia y Bioanálisis, Universidad de Los Andes, en el período comprendido entre enero del 2010 y diciembre del 2016, se procesaron un total de 25.032 muestras citológicas de cuello uterino, de las cuales $580(2,32 \%)$ presentaron anormalidades en células epiteliales, tanto escamosas como glandulares, de las cuales 0,34\% (84/580) fueron interpretadas como ASC-H. La edad promedio de los casos incluidos y con resultado citológico de cuello uterino inicial compatible con $A S C$ - $H$ fue de 46,5 años, sin diferencias estadísticas significativas entre edad y biopsia benigna o anormal ( $p=0,088)$.

En la tabla 1 se muestra la distribución de los hallazgos histopatológicos en la biopsia obtenida posterior e inmediata al resultado citológico de cuello uterino inicial compatible con $A S C-H$. El 35,8\% (19/53) de éstos presentaron un resultado histopatológico anormal, resaltando que 22,6\% revelaron sólo infección por $H P V$ y 13,2\% tenía una lesión premaligna $(C I N)$ e infección por $H P V$. No hubo ningún caso de cáncer invasor ni diferencias estadísticas significativas entre los resultados benignos y los anormales ( $p=0,137)$. Al 45,3\% no se les realizó biopsia. En las historias clínicas correspondientes se encontró que $17 \%$ de los casos $A S C-H$ (9/53) tenían una
Tabla 1. Hallazgos histopatológicos posteriores al resultado citológico compatible con ASC-H $(\mathrm{p}=0,137)$

\begin{tabular}{|l|c|}
\hline \multicolumn{1}{|c|}{ Resultado histopatológico } & Frecuencia (\%) \\
\hline Negativo / benigno* & $10(18,9 \%)$ \\
HPV** & $12(22,6 \%)$ \\
Neoplasia intraepitelialcervical 1/ HPV & $4(7,5 \%)$ \\
Neoplasia intraepitelialcervical 2/ HPV & $1(1,9 \%)$ \\
Neoplasia intraepitelialcervical 3/ HPV & $2(3,8 \%)$ \\
Cáncer invasor & $0(0,0 \%)$ \\
No se realizó el estudio & $24(45,3 \%)$ \\
TOTAL & $\mathbf{5 3 ( 1 0 0 , 0 \% )}$ \\
\hline
\end{tabular}

*Benigno incluye: metaplasias malphigiana y glandular, cambios glandulares reactivos y fibrosis. **HPV: virus de papiloma humano.

prueba molecular para detección y genotipificación de $H P V$, de los cuales $3(33,3 \%)$ resultaron negativos y $6(66,7 \%) \mathrm{HPV}$ positivas. Los genotipos de $H P V$ detectados fueron: 2 casos HPV16 (22,3\%), 1 con HPV18 (11,1\%), 1 caso HPV6 (11,1\%), 1 de $H P V 42(11,1 \%)$ y otro no determinado o $H P V X(11,1 \%)$.

Los principales criterios citomorfológicos representativos de $A S C-H$ presentes tanto en células metaplásicas inmaduras como en células profundas así como el fondo del frotis se detallan en la tabla 2 y por separado según el resultado de la biopsia con incremento de la relación núcleo/citoplasma (por aumento del tamaño nuclear), membrana nuclear y cromatina ligeramente irregular, anisocariosis e hipercromasia nuclear de variable intensidad sobre un fondo de frotis limpio, inflamatorio o sanguinolento. Los extendidos citológicos cuyo posterior hallazgo histopatológico fue benigno mostraron que en $6 / 10(60,0 \%)$ las atipias estaban presentes en células escamosas profundas, mientras que en las pacientes cuya biopsia fue compatible con CIN1, 2 o 3 y/o HPV se encontró que la mayoría $(73,7 \%)$ tenían atipias en células metaplásicas inmaduras. Los criterios citomorfológicos más frecuentes en células metaplásicas atípicas, tanto para los resultados histopatológicos benignos como de CIN1, 2 o 3 y/o HPV, fueron: hipercromasia $2 / 4(50,0 \%)$ y $11 / 14(78,6 \%)$ p $<0,0117$; anisocariosis $4 / 4 \quad(100,0 \%)$ y $14 / 14 \quad(100,0 \%) \quad p<0,0309$; cromatina y membrana nuclear irregular $1 / 4 \quad(25,0 \%)$ y 13/14 (92,9\%) p<0,0117, respectivamente, con diferencias estadísticas significativas entre las atipias presentes en las células metaplásicas con resultado de biopsiaCIN1, 2 o 3 y/o HPV y aquellas con biopsia benigna. En los casos con células escamosas profundas atípicas, tanto para los resultados histopatológicos benignos como de CIN1, 2 o 3 y/o HPV, los hallazgos citológicos fueron: hipercromasia $5 / 6(83,3 \%)$ y 5/5 $(100,0 \%) p=1,000$, anisocariosis $6 / 6(100,0 \%)$ y $5 / 5(100,0 \%)$ $\mathrm{p}=1,000$, cromatina y membrana nuclear irregular $2 / 6$ $(33,3 \%)$ y $5 / 5(100,0 \%) \mathrm{p}=0,688$ respectivamente, en especial cuando el fondo del frotis era inflamatorio $4 / 6(66,6 \%)$ y sin diferencias estadísticas significativas entre las pacientes con biopsia benigna/atrofia y aquellas con CIN1, 2 o 3 y/o HPV. Las figuras 1 a 5 ilustran citológicamente algunos de los principales casos de este estudio. 
Tabla 2. Criterios cito-morfológicos en muestras citológicas de cuello uterino categorizadas con ASC-H y el resultado histopatológico

\begin{tabular}{|c|c|c|c|c|c|}
\hline Tipo celular atípico & $\begin{array}{c}\text { Criterios } \\
\text { citomorfológicos }\end{array}$ & $\begin{array}{l}\text { Benigna } \\
(n=10)\end{array}$ & $\begin{array}{c}\text { CIN y/o HPV } \\
(n=19)\end{array}$ & Frecuencia & Valor p \\
\hline \multirow{11}{*}{$\begin{array}{l}\text { Células metaplásicas } \\
\text { inmaduras } \\
\text { (18) }\end{array}$} & Hipercromasia & $2 / 4$ & $11 / 14$ & $13 / 18(72,22 \%)$ & $p<0,0117$ \\
\hline & Pérdida de la relación N/C & $0 / 4$ & $1 / 14$ & $1 / 18(5,55 \%)$ & --------- \\
\hline & Anisocariosis & $4 / 4$ & $14 / 14$ & $18 / 18(100 \%)$ & $p<0,0309$ \\
\hline & $\begin{array}{c}\text { Cromatina y } \\
\text { membrana irregular }\end{array}$ & $1 / 4$ & $13 / 14$ & $14 / 18(77,77 \%)$ & $p<0,0117$ \\
\hline & Fondo de frotis limpio & $2 / 4$ & $5 / 14$ & $7 / 18(38,88 \%)$ & $p=0,754$ \\
\hline & $\begin{array}{l}\text { Fondo de frotis } \\
\text { inflamatorio }\end{array}$ & $2 / 4$ & $6 / 14$ & $8 / 18(44,44 \%)$ & $p=0,454$ \\
\hline & $\begin{array}{l}\text { Fondo de frotis } \\
\text { sanguinolento }\end{array}$ & $0 / 4$ & $3 / 14$ & $3 / 18(16,66 \%)$ & --------- \\
\hline & *Binucleación & $0 / 4$ & $3 / 14$ & $3 / 18(16,66 \%)$ & --------- \\
\hline & *Multinucleación & $1 / 4$ & $0 / 14$ & $1 / 18(5,55 \%)$ & --------- \\
\hline & *Pleomorfismo nuclear & $2 / 4$ & $3 / 14$ & $5 / 18(27,77 \%)$ & $p=0,625$ \\
\hline & Núcleos sueltos atípicos & $0 / 4$ & $1 / 14$ & $1 / 18(5,55 \%)$ & -------- \\
\hline \multirow{10}{*}{$\begin{array}{c}\text { Células profundas } \\
\text { (11) }\end{array}$} & Hipercromasia & $5 / 6$ & $5 / 5$ & $10 / 11(90,90 \%)$ & $p=1,000$ \\
\hline & Pérdida de la relación N/C & $0 / 6$ & $0 / 5$ & $0 / 11(0,00 \%)$ & -------- \\
\hline & Anisocariosis & $6 / 6$ & $5 / 5$ & $11 / 11(100,00 \%)$ & $p=1,000$ \\
\hline & $\begin{array}{c}\text { Cromatina y } \\
\text { membrana irregular }\end{array}$ & $2 / 6$ & $5 / 5$ & $7 / 11(63,63 \%)$ & $p=0,688$ \\
\hline & Fondo de frotis limpio & $2 / 6$ & $2 / 5$ & $4 / 11(36,36 \%)$ & $p=1,000$ \\
\hline & $\begin{array}{l}\text { Fondo de frotis } \\
\text { inflamatorio }\end{array}$ & $4 / 6$ & $3 / 5$ & $7 / 11(63,63 \%)$ & $p=1,000$ \\
\hline & $\begin{array}{l}\text { Fondo de frotis } \\
\text { sanguinolento }\end{array}$ & $0 / 6$ & $0 / 5$ & $0 / 11(0,00 \%)$ & --------- \\
\hline & *Binucleación & $1 / 6$ & $1 / 5$ & $2 / 11(18,18 \%)$ & -------- \\
\hline & *Multinucleación & $4 / 6$ & $1 / 5$ & $5 / 11(45,45 \%)$ & $\mathrm{p}=0,625$ \\
\hline & *Pleomorfismo nuclear & $2 / 6$ & $2 / 5$ & $4 / 11(36,36 \%)$ & $p=1,000$ \\
\hline
\end{tabular}

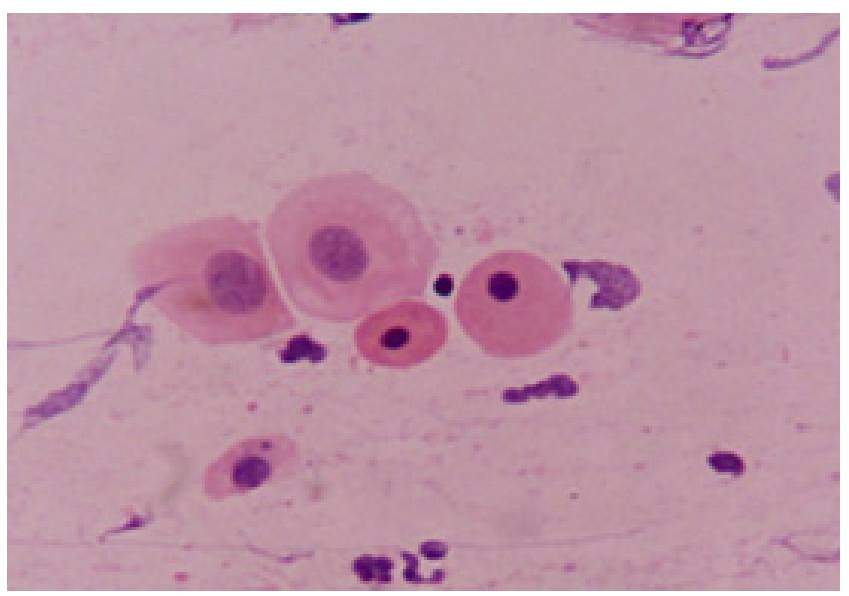

Figura 1. Células escamosas cervicales inmaduras profundas normales con núcleo vesiculoso, redondo u ovalado y cromatina homogénea, otras con cambios reactivos probablemente degenerativos y propios de atrofia: picnosis (40X coloración de Papanicolaou).

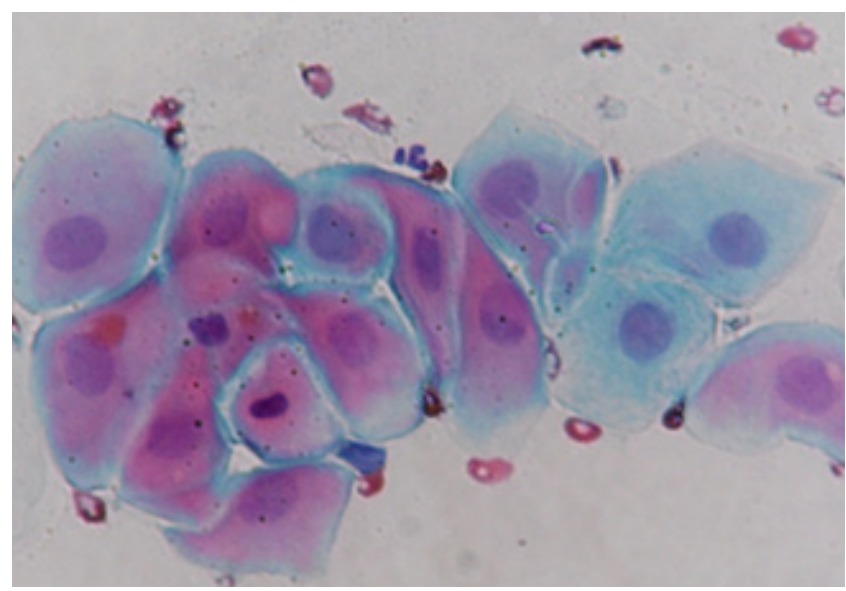

Figura 2. Citología de cuello uterino con células metaplásicas maduras normales con núcleo vesiculoso, redondo u ovalado, membrana uniforme y cromatina homogénea, citoplasma denso y bitintorial. Eritrocitos necrosados (40X coloración de Papanicolaou). 


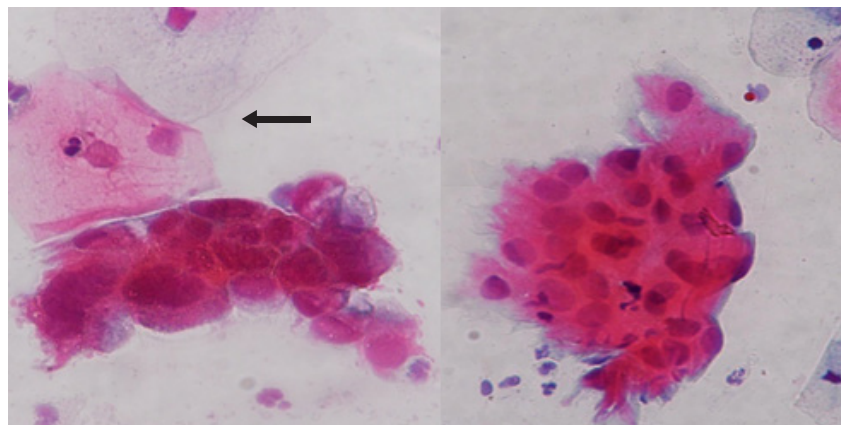

Figura 3. Citología del caso ASC-H 1122/2010. Paciente de 24 años. ZINCN. Células metaplásicas inmaduras atípicas dispuestas en grupos irregulares (HCG) con anisocariosis, hipercromasia variable, cromatina y membrana nuclear irregular y algunas multinucleadas. Hay células escamosas con discreto aumento del tamaño nuclear (flecha) (40X coloración de Papanicolaou). Citología control: ASC-US. Biopsia de seguimiento: CIN3 / HPV. Genotipificación: HPV16.

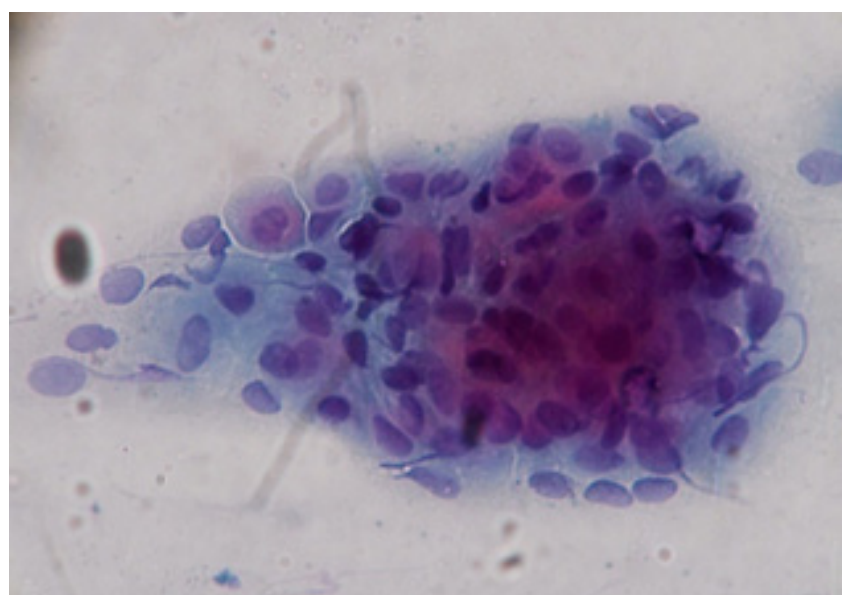

Figura 4. Citología de cuello uterino. Paciente de 64 años. Caso ASC-H 1989/2010. Células escamosas inmaduras profundas, aisladas y en sincicio. Destaca cierto grado de hipercromasia por amontonamiento celular y nuclear, así como discreta anisocariosis, probablemente reactivas (40X coloración de Papanicolaou). Citología control: NILM. No se le realizó biopsia de seguimiento ni prueba de HPV.

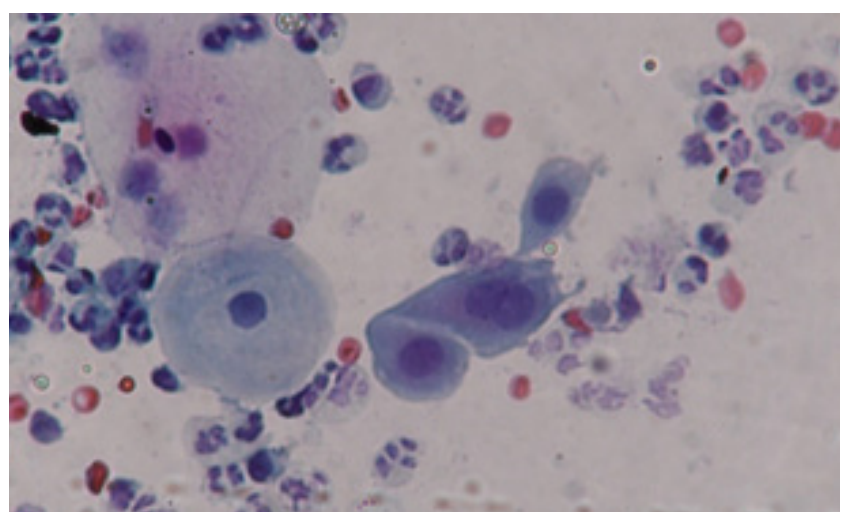

Figura 5. Citología de cuello uterino. Caso ASC-H 718/2010. Paciente de 50 años. ZINCN. Células metaplásicas con discreto aumento del tamaño nuclear y binucleación. Células escamosas maduras e inmaduras sin atipias. Exudado inflamatorio y eritrocitos (40X coloración de Papanicolaou). Citología control: LSIL. Biopsia de seguimiento: HPV. Tipificación: HPV6.

\section{DISCUSIÓN}

El cáncer y las lesiones premalignas pueden originarse a partir del epitelio escamoso o glandular, así como de la zona de transición o metaplasia escamosa del cuello uterino. El sistema Bethesda establece con claridad los criterios cito-morfológicos sospechosos de $H S I L$ incluidos en la subcategoría $A S C-H$, que podrían presentarse en células epiteliales del cuello uterino inmaduras ya sean escamosas y/o metaplásicas. ${ }^{4}$ Este estudio se llevó a cabo con el objetivo de describir las alteraciones citomorfológicas más frecuentes en los extendidos citológicos de cuello uterino categorizados como $A S C-H$, con existencia de lesión clínicamente significativa en el resultado histopatológico, resaltando que el 35,8\% de los casos presentaron un resultado anormal, el 22,6\% revelaron sólo infección por $H P V$ y 13,2\% tenía una lesión premaligna $(C I N)$ combinada con infección por HPV, encontrándose que la hipercromasia, anisocariosis, cromatina y membrana nuclear irregular se asociaron de manera significativa con $C I N 1,2$ o $3 \mathrm{y} / \mathrm{o} H P V$, coincidiendo con lo hallado por otros autores. ${ }^{6,13-16}$

En pacientes jóvenes con presencia de grupos hipercómicos amontonados (HCG, siglas en inglés), que si bien se suelen apreciar en situaciones benignas, también pueden desprenderse de tejidos con lesiones intrapiteliales ${ }^{17}$, sobre todo como los ilustrados en la figura 3 con anisocariosis, hipercromasia, borde nuclear y cromatina irregular. Estos hallazgos sugieren que los criterios podrían usarse de manera confiable como predictivos de $C I N$ 2/3 durante la pesquisa de rutina, siempre en correlación con la información clínica aportada y además deben corroborarse con estudios futuros que incluyan un mayor número de casos. Así mismo, se debe tener presente que el papilomavirus puede inducir la aparición de atipias en células epiteliales infectadas como multinucleación y pleomorfismo nuclear ${ }^{12}$, que fueron encontradas en varios de los extendidos citológicos $A S C-H$ de este estudio y cuyo informe histopatológico confirmó la existencia de infección por $H P V$. Es por ello que en la pesquisa de rutina se debe considerar la posibilidad de que las atipias en células epiteliales del cuello uterino se asocien con esta infección viral, en especial en pacientes jóvenes, debiendo categorizarse como atipias posiblemente asociadas con $H P V$, si no existen criterios claros sugestivos de neoplasia. En ello contribuiría de manera importante el conocimiento de la existencia o no de infección por $H P V$ de tipo oncogénico, lo cual mejoraría el discernimiento de la presencia de atipias celulares sospechosas.

Se ha comprobado que un frotis citológico consistente con $A S C-H$ tiene bajo valor predictivo positivo para neoplasia subyacente en pacientes posmenopáusicas. ${ }^{6}$ Por lo que una observación importante de este estudio fue que la mayoría de los casos $A S C-H$ en pacientes postmenopáusicas presentaron las atipias en células escamosas profundas, sobre un fondo de frotis inflamatorio, consistente con un cuadro citológico de vaginitis atrófica, siendo el resultado histopatológico benigno. Este hallazgo aun cuando no forma parte del objetivo principal 
es de interés y es similar al encontrado por Allí \& Ali 2003 y Michelowy col. 2010. ${ }^{14,15}$ Es posible que entre los cambios degenerativos por atrofia resalten alteraciones que más bien deben considerarse como una atipia reactiva, en vez de una atipia a favor de neoplasia de alto grado o HSIL, más aún si son HPV negativas. ${ }^{4,18}$ Por ello y debido a que no existen aún criterios bien establecidos que puedan usarse para distinguir con certeza entre cambios reactivos y atipias posiblemente asociadas con neoplasia, sugerimos que al evaluar los frotis atróficos de cuello uterino se tome en cuenta la posibilidad de que las alteraciones corresponden a atipia reactiva, en vez de neoplasia $(H S I L)$, más aún si la paciente es negativa para infección por $H P V$ oncogénico. Este dilema de interpretación de cambios o alteraciones celulares puede presentarse también en pacientes embarazadas, en período de posparto y en usuarias de anticonceptivos orales, en las que una disminución relativa de los niveles estrogénicos puede inducir la aparición de atipias reactivas. Aunque se debe ser cauteloso en estos casos pues por ser jóvenes o en edad reproductiva no se puede excluir la presencia oculta de una lesión clínica significativa como lo mencionan Pattony col. 2008. ${ }^{6}$ Por lo que, según consenso, en estos casos es importante conocer la edad y el estatus hormonal de las pacientes y realizar un control postratamiento o según criterio clínico para reevaluar el cuadro citológico y así evitar sobrevalorar hallazgos benignos-reactivos como posiblemente displásicos. En este estudio es relevante el grupo con lesión confirmada por biopsia (CIN / HPV), sin embargo para diagnóstico diferencial, en la rutina de laboratorio, los hallazgos de este trabajo conllevan a considerar la posibilidad de pensar que cuando las atipias están presentes en células profundas con fondo inflamatorio se debe tener la precaución de que las atipias pueden estar asociadas con vaginitis atrófica y no con una lesión premaligna o maligna; es decir, permite evitar la sobrevaloración de las muestras. Para confirmar estas observaciones iniciales se requieren otros estudios con un mayor número de casos para comparar.

Por último, es importante señalar que $45 \%$ de los casos ASC-H no tuvieron estudio histopatológico. Según Selvaggi 2003 y Massady col. 2013 2,9 es necesario aclarar mediante seguimiento clínico que incluye biopsia, el origen de las atipias sospechosas de neoplasia, en especial en pacientes menores de 40 años.

Los hallazgos de este estudio permitieron alcanzar las siguientes conclusiones: 1) los criterios citomorfológicos que deben considerarse para designar un extendido citológico como sospechoso de HSIL incluyen principalmente: anisocariosis, hipercromasia, cromatina y membrana nuclear irregular, sobre un fondo de frotis limpio de elementos inflamatorios, ya que estos se asociaron de manera significativa con CINl, 2 o 3 y/o $H P V$. Dichas alteraciones deben correlacionarse con datos clínicos aportados como edad, hallazgo colposcópico y estatus de infección por $H P V$. 2) Es importante tener en cuenta las atipias inducidas por $H P V$ de alto riesgo oncogénico como binucleación, multinucleación y pleomorfismo nuclear, para evitar una sobrevaloración de los hallazgos citológicos como posible displasia. 3) La presencia de células metaplásicas inmaduras atípicas es más sugestiva de una lesión premaligna sobre todo si la paciente es $H P V$ oncogénico positivo, mientras que las atipias en células escamosas inmaduras profundas podrían ser una consecuencia reactiva del proceso degenerativo por atrofia epitelial. Considerando el análisis anterior, se recomienda que ante la sospecha citológica de $C I N$ es importante realizar una evaluación citomorfológica cuidadosa, siempre en correlación con los datos clínicos de la paciente, con el fin de evitar sobrevaloración de los hallazgos citológicos y realizar procedimientos clínicos innecesarios. En los casos donde las atipias pudieran ser de carácter reactivo por desbalance hormonal, es mejor repetir el análisis citológico para constatar desaparición o persistencia de las atipias, sobre todo en pacientes posmenopáusicas.

CONFLICTO DE INTERÉS

Los autores declaran no tener ningún conflicto de interés.

\section{AGR A D E C I MIENTOS}

Al personal de la Cátedra de Citología y de la Clínica de Prevención del Cáncer de la Sociedad Anticancerosa, Capítulo Mérida, por facilitar sus datos e historias clínicas para el desarrollo de este estudio.

\section{REFERENCIAS}

1. López-Alegría F., Soares L., Poblete O. Follow-up of women with atypical squamous cells cannot exclude high-grade squamous intraepithelial lesions (ASC-H). 2014. Sao Paulo Med J; 132(1), 1522.

2. Massad L., Einstein M., Huh W. Katki H., Kinney W., Schiffman M., Solomon D., Wentzensen N., Lawson H. 2012 ASCCP Consensus Guidelines Conference. 2012 updated consensus guidelines for the management of abnormal cervical cancer screening tests and cancer precursors. 2013. Obstet Gynecol. 121:829-846. doi: 10.1097/AOG.0b013e3182883a34.

3. Davey D. Cytopathology update on atypical squamous cells. J Low Genit Tract Dis. 2005;9:124-129.

4. Abdul-Karim F., Powers C., Berek J., Sherman M., TabbaraS.,Sidawy M. En:Nayar R., Wilbur D.Editors.The Bethesda System for Reporting Cervical Cytology Definitions, Criteria, and Explanatory Notes. Springer. $3^{\circ}$ ed. 2015, Cap. 4: Atypical squamous Cells. Pags:103-134. ISBN 978-3-319-11074-5. 
5. Gilani S., Tashjian R., Fathallah L. Cervical cytology with a diagnosis of atypical squamous cells, cannot exclude high-grade squamous intraepithelial lesion (ASC-H): a follow-up study with corresponding histology and significance of predicting dysplasia by human papillomavirus (HPV) DNA testing. 2010. Arch GynecolObstet, 289:645-648.

6. Patton A., Duncan L., Bloom L., Phaneuf G., Zafar N. Atypical squamous cells, cannot exclude a high-grade intraepithelial lesion and its clinical significance in postmenopausal, pregnant, postpartum, and contraceptive-use patients. 2008. Cancer; 114(6), 481-8.

7. López M., Guillén M., QuinteroM., Cruz J., Puig J., Toro M. Infección por virus papiloma humano en pacientes con células escamosas atípicas de un programa de pesquisa de cáncer cervical. 2012. Obstetricia y ginecología Venezuela, 72(4), 19-27.

8. Türkmen I., Bassüllü N., Korkmaz P., Günenç B., Baykal C., Güdücü N., Isçi H., Dünder I., BülbülG. Patients with Epithelial Cell Abnormality in PAP Smears: Correlation of Results with Follow-Up Smears and Cervical Biopsies. 2013. Turkish Journal of Pathology, 29: 179-181.

9. Selvaggi S. Reporting of atypical squamous cells cannot exclude a high-grade squamous intraepithelial lesion (ASC-H) on cervical samples: Is it significant?.Diagn. Cytopathol. 2003; 29:38-41.

10. Bonvicino A., Huitron S., Fadare, O. Papanicolaou test interpretations of "atypical squamous cells, cannot exclude high-grade squamous intraepithelial lesion": an investigation of requisite duration and number of colposcopic procedures to a definitive diagnosis of highgrade dysplasia in routine practice. 2007. Cancer; $111(6), 477-81$.

11. Toro de Méndez M, López de Sánchez M, Omaña de Uzcátegui T, Altuve de Acuña F, Guillén FerraroM.Hallazgos histopatológicos asociados acélulas glandulares atípicas. Revista de la Facultad de Farmacia. 2005;47:2-4.
12. Mendez L., Rodriguez A., Lopez M., Toro M. Signos citológicos no clásicos asociados a la infección por el Virus del Papiloma Humano (VPH) en pacientes de Merida, Venezuela. 2011. InvestClin. 52(2): 162-169.

13. McGrath C. ASCUS in papanicolaou Smears: Problems, Controversies, and potential Future Directions. 2002.Pathology Patterns Reviews.117, 15-22.

14. Allí P., Ali S. Atypical squamous cells of undertermined significance rule out high grade squamous intraepithelial lesion: cytopathologic characteristics and clinical correlates 2003. Diagnostic Cytopathology. 28:308-312.

15. Michelow P., Hartman I., Schulze D., Lamla-Hillie S., Williams S., Levin S., Firnhaber C. Atypical squamous cells, cannot exclude high grade aquamous intraepithelial (ASC-H) in HIV-positive women. 2010. Cytojournal. 7:8.

16. Atjimakul T., Boonyapipat S., Chichareon S., Phukaoloun. Citomorphologic and clinical factors of having high grade cervical intraepithelial neoplasia/invasive carcinoma in women with atypical squamous cells,cannot exclude high grade squamous intraepithelial lesions (ASC-H) smears. 2013. Med Assoc Thai. 96 (11) 1389-1394.

17. Chivukula M., Shidham V.ASC-H in Pap test-definitive categorization of cytomorphological spectrum. 2010. Cytojournal. 10;3:14.

18. Johnston E., Logani S. Cytologic diagnosis of atypical squamous cells of undetermined significance in perimenopausal and postmenopausal women: lessons learned from human Papillomavirus DNA testing. 2007. Cancer.111:160-165. 